\title{
Aneurysmal Bone Cysts of the Cervical Spine
}

\author{
Jung Min Lee', Seung Chul Rhim, Dong Ho Lee ${ }^{2}$, Joon Seon Song ${ }^{3}$ \\ Departments of ${ }^{1}$ Neurosurgery, ${ }^{2}$ Orthopedic Surgery, ${ }^{3}$ Pathology, Asan Medical Center, \\ University of Ulsan College of Medicine, Seoul, Korea
}

Aneurysmal bone cysts (ABCs) are expandable non-neoplastic tumor-like lesions and possess a unique pathology reflecting the presence of blood filled cavities within the lesion. They comprise about $1.4 \%$ of all bone tumors and $15 \%$ of all primary spine neoplasm. Cervical spine of $A B C$ s are only $2 \%$ of all $A B C s$. $A B C$, originated from middle column of cervical spine with encasing vertebral artery is very rare. We will discuss our experience of the case mentioned above in this report.

Key Words: Bone cysts · Aneurysmal $\cdot$ Vertebral artery $\cdot$ Spine

\section{INTRODUCTION}

Aneurysmal bone cysts (ABCs) are expandable non-neoplastic tumor-like lesions and possess a unique pathology reflecting the presence of blood filled cavities within the lesion ${ }^{4)}$. Although most clinically diagnosed ABCs are observed in the metaphyseal region of long bones, approximately $10 \%$ to $30 \%$ of $\mathrm{ABCs}$ arise in the spine and contribute to approximately $15 \%$ of all primary spine bone tumors ${ }^{13)}$. They usually affect young adolescents and can cause symptoms such as back pain, neuro- logic deficits, and pathologic fractures ${ }^{1)}$. As ABCs were rare entity, no clear indication for any of the treatment modality has been described. We report a case of cervical spine $\mathrm{ABC}$, treated with curettage through bone grafting.

\section{CASE REPORT}

A 16-year-old boy admitted to neurosurgery department with neck pain when turning his head to the right side. Except neck pain, he did not showed focal neurologic symptom and sign. Computed tomography (CT), vertebral arteriography showed multi-lobulated lytic lesion with multiple internal septations in $\mathrm{C} 1$ spine. Cervical magnetic resonance imaging (MRI) revealed well-defined lobulated osteolytic mass $(2.0 \times 1.5 \times 1.8$ $\mathrm{cm}$ ), with rim enhancement in the right lateral mass of $\mathrm{C} 1$ spine (Fig. 1). The lesion showed internal septation with fluid-

Corresponding author: Seung Chul Rhim, MD, PhD

Department of Neurosurgery, Asan Medical Center, University of Ulsan College of Medicine, 13, Gangdong-daero, Songpa-gu, Seoul 05505, Korea Tel: +82-2-3010-3550, Fax: +82-2-476-6738

E-mail: scrhim@amc.seoul.kr fluid level and encasing right vertebral artery (VA) (Fig. 2). Because the mass was encasing the VA, we planned lesion curettage rather than en-bloc resection. We performed right C1 lateral mass curettage, and filled with autologous posterior superior iliac bone graft. During the surgery, there was no injury to VA. He had no focal neurological deficit after the surgery. Three months after surgery, the patient's neck pain was improved.

\section{DISCUSSION}

$\mathrm{ABC}$ was identified as a distinct clinicopathologic entity in 1942 by Jaffe and Lichtenstein ${ }^{4)}$. ABC comprises about $1.4 \%$ of all bone tumors and 15\% of all primary spine neoplasms ${ }^{6}$. And on the spine, lumbar involvement (34\%) is followed by thoracic spine (32\%) and uncommon in the cervical spine ${ }^{3)}$. Cervical spine of $\mathrm{ABC}$ are only $2 \%$ of all $\mathrm{ABCs}^{9}$. $\mathrm{ABCs}$ in the

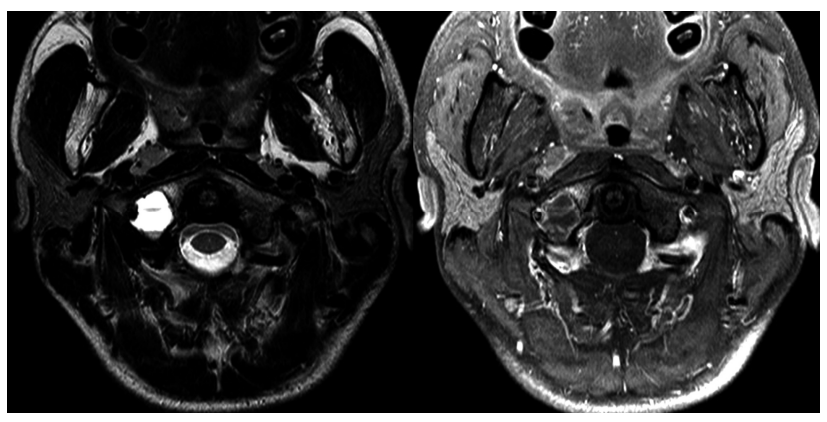

Fig. 1. A $2 \times 1.5 \mathrm{~cm}$ lobulating osteolytic lesion with rim enhancement in the right lateral mass of $\mathrm{Cl}$. The lesion has well-defined osteosclerotic margin with internal septation with fluid-fluid level (T2 with non-contrast and $\mathrm{T} 1$ with contrast images of cervical magnetic resonance imaging). 


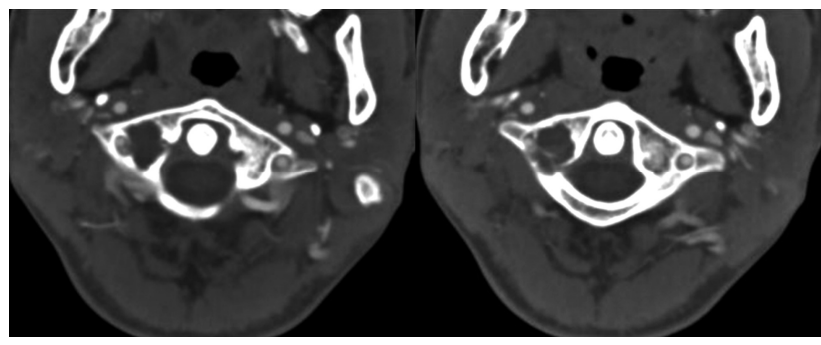

Fig. 2. CT, vertebral arteriography shows multilobulated lytic lesion with multiple internal septations at $\mathrm{Cl}$ lateral mass, Rt. which encasing Rt. VA.

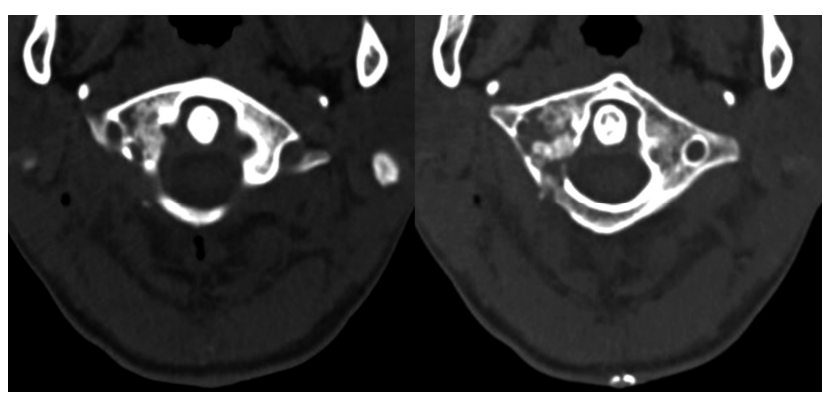

Fig. 3. Postoperative computed tomography shows insertion of harvested bone at the site of resected cystic mass.

usually arises from posterior osseous elements and may spread to another vertebrae, adjacent rib, paraspinal soft tissues ${ }^{1)}$. Therefore, our case is rare because $\mathrm{ABC}$ was located at middle column (lateral mass) of upper cervical spine with encasing VA.

Usually biopsy is used on $\mathrm{ABC}$ diagnosis, the combination of radiographs, $\mathrm{CT}$ scans, and MRI could be useful for diagnosis of $\mathrm{ABC}^{5}$. On $\mathrm{CT}, \mathrm{ABC}$ appears as a multi-lobulated lytic lesion with multiple internal septations and fluid levels ${ }^{7}$. Liu et al. ${ }^{6}$ reported that the presence of multi-lobular cysts with fluid-fluid levels on T2 weighted MRI images is highly suggestive of $A B C$. At this case, we could assume that the tumor was cervical $\mathrm{ABC}$ because CT scan and MRI findings are consistent with the typical $\mathrm{ABC}$, even if it does not consistent with the biopsy findings. In the paper of Wang et al. ${ }^{14)}$, accuracy of biopsy was only $43 \%$. Except en-bloc removal of the tumor, the biopsy should be taken for the cyst's internal wall or from ant intralesional septum $^{11)}$. We took the intralesional septum for biopsy specimens, but the biopsy result was not consistent with the typical $\mathrm{ABC}$. The reason we thought are as follows: insufficient specimens or inappropriate location for biopsy, where the tumor cell were scanty.

Treatment options for ABCs include intralesional curettage with or without bone grafting, complete excision, arterial embolization, intralesional drug injections (steroid and calcitonin) and radiation or a combination of these options ${ }^{1,2}$. Spontaneous regression of the tumor is uncommon ${ }^{10)}$. The most impor- tant factors in preoperative planning are the location and the growing pattern of the $\mathrm{ABC}^{8)}$. Besides, the VA that is generally encasing by the lesion is the most important anatomical structure that must be protected. Although surgical removal has the lowest rate of local recurrence, it may prove to be surgically challenging or even impossible, depending on the location and on the intraoperative blood loss. Because of a high index of VA rupture in en bloc spondylectomy, total excision by curettage with a high speed drill or piecemeal resection is a generally accepted surgical option ${ }^{12)}$. In this case, curettage with bone grafting was chosen to protect VA because the tumor was located at right $\mathrm{C} 1$ lateral mass and VA was encased by the lesion. By this choice, we could save VA from damage and finish the surgery safely.

\section{CONCLUSION}

$\mathrm{ABC}$ at cervical spine is not common. When the lesion is encasing VA, curettage can be a surgical option to avoid damage to the VA.

\section{REFERENCES}

1. Boriani S, De Iure F, Campanacci L, Gasbarrini A, Bandiera S, Biagini R, et al.: Aneurysmal bone cyst of the mobile spine: report on 41 cases. Spine (Phila Pa 1976) 26:27-35, 2001

2. Harrop JS, Schmidt MH, Boriani S, Shaffrey CI: Aggressive "benign" primary spine neoplasms: osteoblastoma, aneurysmal bone cyst, and giant cell tumor. Spine (Phila Pa 1976) 34:S39S47, 2009

3. Hay MC, Paterson D, Taylor TK: Aneurysmal bone cysts of the spine. J Bone Joint Surg Br 60B:406-411, 1978

4. Jaffe HL, Lichtenstein L: Solitary unicameral bone cyst with emphasis on the roentgen picture, the pathologic appearance and the pathogenesis. Arch Surg 44:1004-1025, 1942

5. Kitamura T, Ikuta K, Senba H, Komiya N, Shidahara S: Longterm follow-up of a case of aneurysmal bone cyst in the lumbar spine. Spine J 13:e55-e58, 2013

6. Liu JK, Brockmeyer DL, Dailey AT, Schmidt MH: Surgical management of aneurysmal bone cysts of the spine. Neurosurg Focus 15:E4, 2003

7. Murphey MD, Andrews CL, Flemming DJ, Temple HT, Smith WS, Smirniotopoulos JG: From the archives of the AFIP. Primary tumors of the spine: radiologic pathologic correlation. Radiographics 16:1131-1158, 1996

8. Ozdemir S, Yaldiz C, Ozden F, Kacira OK, Kacira T: Aneurysmal bone cysts of the spine: two case reports. Korean J Spine 11: 249-251, 2014

9. Pennekamp W, Peters S, Schinkel C, Kuhnen C, Nicolas V, Muhr $\mathrm{G}$, et al.: Aneurysmal bone cyst of the cervical spine (2008:7b). Eur Radiol 18:2356-2360, 2008

10. Sağlik Y, Kapicioğlu MI, Güzel B: Spontaneous regression of 
aneurysmal bone cyst. A case report. Arch Orthop Trauma Surg 112:203-204, 1993

11. Sebaaly A, Ghostine B, Kreichati G, Mallet JF, Glorion C, Moussa R, et al.: Aneurysmal Bone Cyst of the Cervical Spine in Children: A Review and a Focus on Available Treatment Options. J Pediatr Orthop 35:693-702, 2015

12. Tonomura ET, Ramos P, Hemais PM, Marchiori E, Gasparetto EL: Aneurysmal bone cyst at C2: imaging evaluation after intra- lesional injection of calcitonin and methylprednisolone. Arq Neuropsiquiatr 66:711-715, 2008

13. Vergel De Dios AM, Bond JR, Shives TC, McLeod RA, Unni KK: Aneurysmal bone cyst. A clinicopathologic study of 238 cases. Cancer 69:2921-2931, 1992

14. Wang C, Liu X, Jiang L, Yang S, Wei F, Wu F, et al.: Treatments for primary aneurysmal bone cysts of the cervical spine: experience of 14 cases. Chin Med J (Engl) 127:4082-4086, 2014 